\title{
Nano meets the sheet: adhesive-free application of nanocellulosic suspensions in paper conservation
}

\author{
L. Völkel ${ }^{1}$, K. Ahn², U. Hähner ${ }^{3}$, W. Gindl-Altmutter ${ }^{4}$ and A. Potthast ${ }^{2 *}$ (D)
}

\begin{abstract}
Historical papers are often locally damaged by exogenous influences and/or have endogenously degraded paper areas. The stabilization of such papers is very important because further use of the object can cause additional damage. Different types of nanocellulose are interesting as a novel stabilizing materials for paper due to their close structural relation to the paper matrix. Therefore, the present study investigated whether the treatment of historical papers with nanocellulose suspensions is a novel method for paper stabilization. Two different types of nanocelluloses, bacterial cellulose and a mechanically nanofibrillated cellulose based on wood pulp, were tested with regard to their performance in stabilizing fragile papers. Concerning material handling and application in conservation steps, different ways to modify the suspensions were tested. The resulting suspensions were applied to historical papers from several centuries with different extents of damage. The paper-nanocellulose composites were characterized with regard to their optical and microscopic integrity and by physical and chemical analyses. The treatment of mechanical damage and the consolidation of weakened paper areas could be realized by the application of a nanocellulose suspension without an additional adhesive. The results of the treatment depend on the type of nanocellulose, on the paper material, on processing and application techniques. The paper discusses the applicability and stability of the differently prepared nanocellulose suspensions, also with regard to their mode of application and long-term performance. Advantages and limitations are addressed in detail.
\end{abstract}

Keywords: Bacterial cellulose, Nanofibrillated cellulose, Paper stabilization, Gel Permeation Chromatography (GPC), Mechanical testing, Aging

\section{Background}

Mechanical damage in form of cracks, cuts, fractures, losses, creases, and deformations very often occur to documents in archives, libraries, and museums. Different types of damage are caused by local and/or external forces acting on single items. Therefore, damage is most often present around the edges. Besides the direct influence, sheet borders are exposed to atmospheric influences that could have a negative effect on the strength properties close to the edge of papers. Poor material

\footnotetext{
*Correspondence: antje.potthast@boku.ac.at

2 Division of Chemistry of Renewables, Department of Chemistry,

University of Natural Resources and Life Sciences (BOKU),

Konrad-Lorenz-Strasse 24, 3430 Tulln, Austria

Full list of author information is available at the end of the article
}

quality and/or endogenous cellulose degradation-as in modern papers from the nineteenth and twentieth centuries-as well as cellulose damage by biodeterioration reduce the strength characteristics of papers and worsen mechanical damage when using those papers. Additionally, most of the dangers in connection with reduced strength properties and prior damage result from the reuse of the items that can cause new damage or intensify already existing defects [1]. Because mechanical damage affects a great number of paper items in collections, stocks, and estates, its treatment is one of the basic and important challenges in restoration work [2]. As far as the treatment of mechanical damage is concerned, the objective is to stabilize weakened papers and rehabilitate extremely damaged areas by adding Japanese paper. At the same time, the substance and quality of 
papers should be preserved in case of further mechanical stress. This should allow for lower risk when handling papers (Fig. 1).

The treatment of papers demands that can be gathered from physical, chemical, and optical aspects. The treatment should provide sufficient strength and generate minimal material enforcement without producing sharp edges; it should not provoke any endogenous changes or potential damage in the long term (like dislocations at fibres), just to name a few examples [3]. Furthermore, stabilizing treatments are very often judged from an aesthetical viewpoint. During stabilizing treatment, there should not be any influencing factors that lead to visual changes on the surface of the paper-this means low gloss, no colour changes, and no harming of the lettering [3].

The traditional method of paper stabilization is to mend with Japanese paper [4-6]. The adhesive is applied to Japanese paper or to the original item via brush application. Both (the Japanese paper and the original item) are subsequently glued together. As far as the processing is concerned, there are some variations, but the basic principle remains unchanged. The selection of the Japanese paper, the adhesive, and the method of treatment is determined by damage symptoms and object characteristics. In this context, and because of the fact that in many cases local damage has to be treated, the development and the increased use of coated stabilizing papers (remoistenable and heat-set tissues) represents an interesting methodical approach. They allow for easier processing of the very thin Japanese tissue papers, a standardization of the adhesive quantity, and the minimization of the influence of moisture or better humidity control during the paper stabilization phase [7, 8]. For this purpose, fabrication and processing technologies are helpful [7-9].

Different types of nanocellulose can be interesting as a novel and innovative materials for paper stabilization due to their strong structural similarity to the paper matrix (i.e., cellulose). In principle, the molecular structure of the bacterial nanocellulose (BNC) and nanofibrillated cellulose (NFC) and that of conventional herbal/ plant-based cellulose is identical. But there are considerable differences at the level of fiber morphology. The nanocelluloses of plant origin and of bacterial origin are characterized by common specific properties that are caused by their molecular construction and their structures in the nanometre range. However, considerable differences are mainly resulting from different production processes. BNC, for example, has-compared with NFC - a higher water retention capacity, a higher degree of polymerization, and more uniform fibres (fibre diameter BNC: $20-100 \mathrm{~nm}$, NFC: $5-100 \mathrm{~nm}$; $[10,11])$. An essential difference lies in the purity level of the nanocelluloses. After a thorough cleaning, BNC can be produced with the highest degree of purity [12]. In contrast, in NFC, additional components (like hemicellulose, lignin, and other substances) are contained, depending

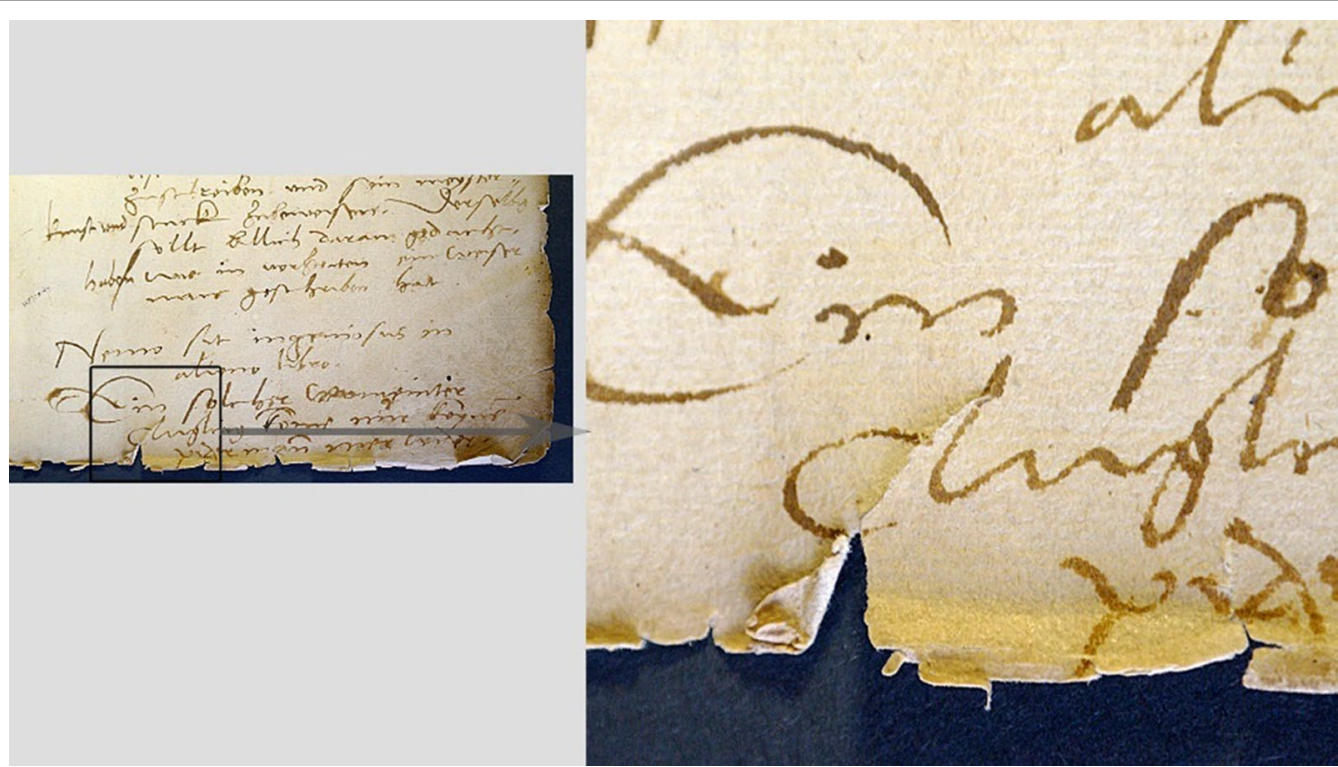

Fig. 1 Mechanical damage (cracks) at the edges of a letter. The scripture is compromised and threatened. (๑ Forschungsbibliothek Gotha der Universität Erfurt, Chart. A 496, p. 3) 
on isolation and cleaning conditions during the production process. For both materials, the emerging nanodimensions require large fibre surfaces that, in turn, cause strong interactions with substances of the environment [11-13].

Bacterial nanocellulose has unique selling points in comparison to cellulose of plant origin due to the manufacturing process. It is synthesized by bacteria of the species Gluconacetobacter. During (in situ) or after (post) biosynthesis, the development of cellulose (i.e., form, structure, etc.) can be individually controlled. After less complex cleaning (cooking in sodium hydroxide solution and washing) compared to the isolation of NFC, bacterial products can be directly used. Moreover, $\mathrm{BNC}$ has a very high molecular weight (species depending, around DP 8000), a high degree of crystallinity, and a distinct mechanical strength $[12,14]$. At the same time, it is also believed that it has an exceptional level of chemical and thermal stability [15]. The high water retention capacity of the undried $\mathrm{BNC}$ is one of its characteristic features $[12,14,16]$. It stores large quantities of water in fibre suspensions that prevent irreversible creations of fibre agglomerates $[12,15]$.

Nanofibrillated cellulose is isolated from cellulosic fibres by using a mechanical or chemo-enzymaticmechanical treatment (top-down-methods). That means structures are extracted from a fibre network by defibrillation [17]. The aim is to split fibres into micro- and nanofibrils without changing the high aspect ratio. Chemical pulp (like kraft or sulfite pulp), vegetable fibres of agricultural or waste products, or fast-growing plants like eucalyptus, sisal, or ramie [18, 19] provide the source of raw materials. Furthermore, unbleached pulp can be fibrillated [20], which is a particularly interesting aspect with reference to (ancient) paper shades. Consequently, it might be possible with respect to NFC to influence the outcome through various parameters during or after the production process. Important key data of NFC are size and size distribution of the fibrils. NFC has also a very good water retention capacity $[10,18]$ and distinct mechanical strength properties [18].

Due to their positive characteristics, like strength increasing and film generating features, they are more and more used for various purposes as additives in the paper industry [12, 21, 22]. Currently, the application of nanocellulose [BNC, NFC, and CNC (cellulose nanocrystals)] in paper conservation is increasing quickly, and approaches vary considerably. Santos et al. used BNC sheets prepared as fleeces for lining or reinforcing papers [23, 24]. A novel type of mending paper of BNC fibres and Japanese fibres was developed by Segers et al.
[25]. Because of the special surface characteristics, it is well-suited for transparent or coated papers, as well as parchment, and can be used to stabilize or to fill losses [25].

The application of NFC has also been investigated, because the strength of paper can be improved by coating or admixture [21]. A complete coating as a new technique for strengthening acidic wood-based, degraded paper was presented by Okayama et al. The strength of those papers were improved by the treatment $[26,27]$. Camargos et al. and Pereira used NFC or CNC mixed with fillers, pigments, plasticizers, and sizing agents to fill paper losses in situ [28, 29]. Another approach is the application of films of microfibrillated cellulose to mend cracks. In particular, the very good optical appearance and the positive mechanical characteristics allowed the application for a special object group like "polyorama panoptique" (paper viewing slides) [30].

The different approaches in the paper industry and in paper conservation and the perfect compatibility of cellulose and nanocellulose lead to the hypothesis that nanofibers bond with fibres of the paper matrices and exert a stabilizing effect without adding additional anchoring materials like adhesives. The central question that will be addressed in this paper is: "Does the treatment of histori$\mathrm{cal} /$ ancient papers using nanocellulose offer a new possibility of paper stabilization without using adhesive additives?" Based on an analytical-empirical research project, the paper especially aims to answer the following questions:

- How do the unique characteristics of nanocelluloses comply with paper conservation treatments?

- What methods can be used to apply nanocellulose suspensions?

- How does nanocellulose influence paper stability on the long run?

\section{Methods \\ Nanocelluloses}

Bacterial nanocellulose/CMC (carboxymethylcellulose) fibres suspensions were obtained from JeNaCell $\mathrm{GmbH}$ (Jena, Germany) in three different average fibre lengths (cf. Table 1). The suspensions varied in their average fibre length. Biosynthesis was performed under shaking, and CMC (Sigma-Aldrich, DP: 400) was added as a modifier (2\%). In the process, short CMC-chains are integrated into fibres, whereby the amount of integrated CMC is not quantified [16]. The composites were received as a $0.5 \%$ suspension in water or water-ethanol.

NFC from bleached softwood kraft pulp was obtained from USDA (Madison, Wisconsin, USA). The 
Table 1 Properties of BNC and NFC suspensions

\begin{tabular}{|c|c|c|c|c|}
\hline & BNC-bacterial cellulose & BNC-bacterial cellulose & BNC-bacterial cellulose & $\begin{array}{l}\text { NFC-nanofibrillated } \\
\text { cellulose }\end{array}$ \\
\hline Fibre type & $\begin{array}{l}\text { Hydronan + fiber } \\
\text { category C2 }\end{array}$ & $\begin{array}{l}\text { Hydronan + fiber } \\
\text { category C1 }\end{array}$ & $\begin{array}{l}\text { Hydronan + fiber } \\
\text { category C4 }\end{array}$ & $\begin{array}{l}\text { CNF (cellulose } \\
\text { nano-fibrils) }\end{array}$ \\
\hline Type/grade & BNC/CMC-composite fibres & BNC/CMC-composite fibres & BNC/CMC-composite fibres & CNF \\
\hline Fibre length & $0.25 \mathrm{~mm}$ & $0.1 \mathrm{~mm}$ & $1 \mathrm{~mm}$ & - \\
\hline $\begin{array}{l}\text { Concentration of } \\
\text { suspension }\end{array}$ & $0.5 \%$ & $0.5 \%$ & $0.5 \%$ & $2.5-3 \%$ \\
\hline $\begin{array}{l}\text { Concentration for } \\
\text { application }\end{array}$ & $0.5 \%$ & $0.5 \%$ & $0.5 \%$ & $0.5 \% / 1 \%$ \\
\hline Suspension solvent & Ethanol-water (33:77)/water & Ethanol-water (33:77)/water & Ethanol-water (33:77)/water & Water \\
\hline Colour & Transparent & Transparent & Transparent & White \\
\hline
\end{tabular}

nanofibrillated fibres are made by mechanical treatment in a high-performance grinding gear (ultrafine grinder, Masuko MKZB15-50J). The fibres are obtained in a suspension with a solid content between 2.5 and $3 \%$ (Table 1).

\section{Modification of suspensions}

Because the water retention capacity of nanocellulose is very high due to extended fibrillation, a suitable concentration method had to be found prior to solvent exchange in order to modify the suspension. Four different concentration methods-filtration, centrifugation, evaporation and freeze drying-were tested. Subsequently, the solvent exchange for $\mathrm{BNC}$ was started by freeze-drying [BETA 1-8 LD plus (Christ)]. Freeze-dried $\mathrm{BNC}$ was subsequently pre-swollen to a water content of $40 \%$ and diluted with $60 \%$ ethanol. The NFC fibres were used as a suspension in a water-ethanol-mixture (40:60).

For modification with gelatin, a $5 \%$ solution (5\%, photographic gelatin type Restoration 1, GMW) was prepared. Freeze-dried BNC was pre-swollen and diluted in $97.5 \%$ water followed by adding $2 \%$ gelatin. During processing, the suspensions were agitated with a magnetic stirrer. In addition, a 2\% SCMC solution (sodium carboxymethylcellulose, Blanose $^{\text {TM }}$ CMC 7H3SF PH, Ashland, USA) was tested on for modification as well. The fibre suspensions $(0.5$ and $1 \%)$ were directly mixed with the SCMC solution.

\section{Model paper}

The types of paper chosen for treatment represent a wide variety of different ages and damage patterns. They can be treated destructively and can be divided in the following two groups: model paper for analytical investigations and model paper with characteristic damages for application-oriented tests.
- Types of model paper for analytical investigations

Rag (II) paper, Whatman filter paper (III), book paper without (IV) and with lignin (V), and newsprint paper (VI) (Table 2) have been naturally aged, but in an unknown way. The properties of the samples applied are given in Table 2.

- Types of model paper with characteristic damages for application-oriented tests

For the application-oriented tests or the individual treatments of local damage, the samples (Table 3) were cut with regard to damage symptoms or/and planned treatments.

\section{Application}

The different types of nanocelluloses were applied to historical papers locally or by full coating. The suspensions were applied with a brush or film applicator on a vacuum panel (mobile vacuum panel RSP1 with plastic sintered plates (hydrophilic, PE), GMW, Germany). Subsequently, the samples were dried in a dry stack for at least $12 \mathrm{~h}$ and used for further analysis.

The amount of the nanocellulose applied was determined for three types of historical paper (rag paper (II), book paper without (IV) and with (V) lignin) and Whatman no. 1 paper (I). The samples were weighed before and after treatment. The moisture content was measured at $105{ }^{\circ} \mathrm{C}$ until constant weight with an infrared moisture analyser (MA 35, Sartorius, Germany).

\section{Accelerated aging}

One part of the samples was submitted to artificial aging based on ASTM-Standard D6819-02e3 [31, 32]. Treated paper samples, references, and films of nanocelluoses were equilibrated in $50 \mathrm{ml} \mathrm{SCHOTT} \mathrm{flasks} \mathrm{up} \mathrm{to} 50 \pm 2 \%$ 


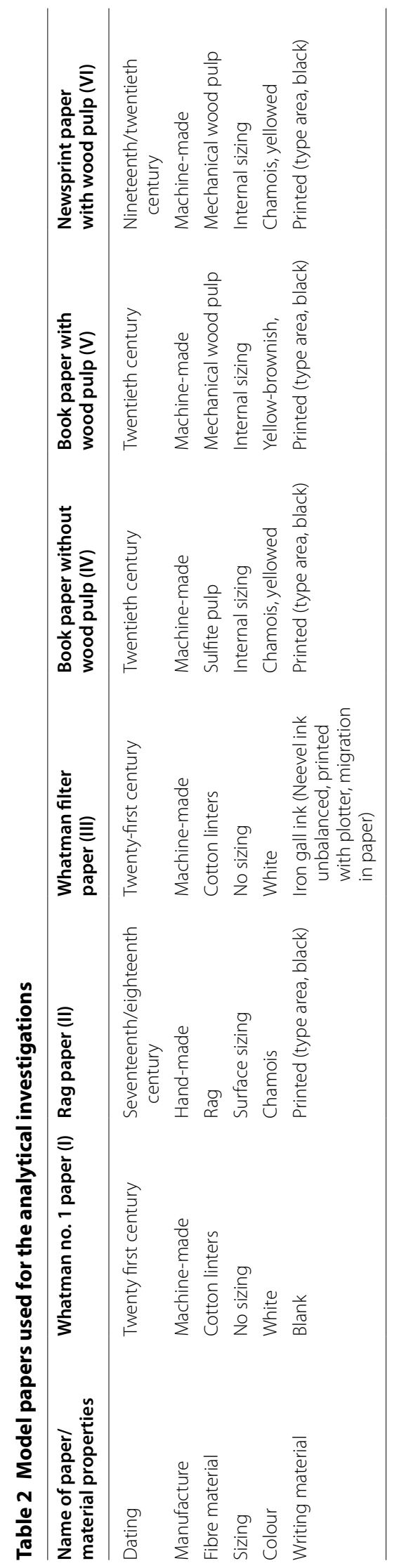


Table 3 Model papers used for the application-oriented tests

\begin{tabular}{|c|c|c|c|c|}
\hline $\begin{array}{l}\text { Name of paper/material } \\
\text { properties }\end{array}$ & Whatman no. 1 paper (I) & Rag paper (VII) & Rag paper (VIII) & $\begin{array}{l}\text { Book paper } \\
\text { with wood pulp (IX) }\end{array}$ \\
\hline Dating & Twenty-first century & Before 1850 & Before 1850 & Twentieth century \\
\hline Manufacture & Machine-made & Hand-made & Hand-made & Machine-made \\
\hline Fibre material & Cotton linters & Rag & Rag & Wood pulp \\
\hline Sizing & No sizing & Surface sizing & Surface sizing & Internal sizing \\
\hline Characteristics & Blank & $\begin{array}{l}\text { Partly blank, partly printed } \\
\text { (black type area) }\end{array}$ & $\begin{array}{l}\text { Varying iron gall ink, partly } \\
\text { migrated }\end{array}$ & Blank \\
\hline
\end{tabular}

relative humidity at $23 \pm 1{ }^{\circ} \mathrm{C}$ according to ISO 187 for $24 \mathrm{~h}$. Subsequently, the airtight flasks were placed at $80{ }^{\circ} \mathrm{C}$ in an oven (UFB 500, Memmert, Germany) for six days $(144 \mathrm{~h})$. A part of the rag (II) and book paper (IV) (800 mg) was aged further in airtight flasks at $80{ }^{\circ} \mathrm{C}$ for another 14 days $(336 \mathrm{~h})$. Local treated samples of Whatman No. 1 paper were aged for optical examinations in airtight flasks by means of cyclical temperature changes [heating $\left(80{ }^{\circ} \mathrm{C}\right)$ and cooling $\left(30{ }^{\circ} \mathrm{C}\right)$ cycles for $6 \mathrm{~h}$ ] for $336 \mathrm{~h}$ or $504 \mathrm{~h}$.

\section{Characterization}

\section{Visual and haptic characterization}

The treated samples were compared with the untreated reference material in a visual (formation of gloss, water edges, of agglomerations or films) and haptic (structure of surface, flexibility, tension, thickness) manner. In addition, it was documented if existing mechanical damage was stabilized or new mechanical damage arose after treatment.

\section{Measurement of ISO brightness}

The measurements of ISO brightness were performed according to DIN ISO 2470 (U-3010, Hitachi, Tokyo, Japan) [33]. The ISO brightness was determined in duplicate or triplicate measurements before and after accelerated aging (6 days) on the same measuring spot [SD $(\mathrm{N}=10)]$.

\section{Microscopy}

Aged samples were investigated by light microscopy at $25 \times$ or $100 \times$ magnification (Axioplan 2 imaging). The surface of the treated rag paper and Whatman no.1 paper and the films of nanocelluloses were examined with SEM (FEI Inspect S50 SEM at $10 \mathrm{kV}$ after approximately $12 \mathrm{~nm}$ of gold coating). The characteristics of BNC and NFC fibres and also the surface properties of BNC and NFC films or treated samples were analysed by AFM (Dimension Icon AFM Bruker). Samples for microscopy were prepared by pouring a drop of diluted dispersion fluid $(0.001 \% \mathrm{w} / \mathrm{w})$ on a quartz crystal platelet that was thereafter left to dry in an oven, or by putting a sample directly on the sampling area $(5 \times 5 \mathrm{~mm})$ on a quartz crystal platelet. Images were taken in tapping mode using a standard silicon cantilever (TESPA, Bruker Corp.)

\section{Measurement of tensile strength}

The measurements of tensile strength were conducted according to ISO 1924-2:2008 standards [34]. Treated paper samples and references were equilibrated to $50 \pm 2 \%$ humidity at $23 \pm 1{ }^{\circ} \mathrm{C}$ according to ISO 187 for $48 \mathrm{~h}$. The samples of $15 \mathrm{~mm}$ wide stripes were measured in a tensile tester (81502-SN41450, Frank Prüfgeräte $\mathrm{GmbH}$, Germany) with 10 repetitions in order to minimize paper inhomogeneity [35]. The average paper thickness in connection with the average paper weight was used as reference value to calculate the measured parameters.

\section{Measurement of zero-span}

Zero-span was analysed based on TAPPI T $231 \mathrm{~cm}-966$ using a Z-Span 1000 Troubleshooter from Pulmac (Williston, VT, USA). Sample strips $(20 \mathrm{~mm})$ were preconditioned for 2 days prior to measurements in a climatic room at $50 \% \mathrm{RH}( \pm 2 \%)$ and $23{ }^{\circ} \mathrm{C}\left( \pm 1^{\circ}\right)$. For each sample, the clamping pressure was adjusted to obtain the maximum breaking force. Eighteen measurements were carried out for each type of paper, usually two to three per paper strip. Results of the measurements were recalculated into breaking force and breaking length.

\section{GPC measurement and fluorescence labelling of carbonyl groups}

The CCOA (carbazole-9-carbonyl-oxy-amine) labelling of carbonyl groups was performed as described earlier [36-38].

\section{Results and discussion}

Bacterial nanocellulose and NFC were applied on different paper samples that represent the types of papers to be treated in the future with specific paper properties to be considered, such as the wettability of papers, which is crucial for treatment with nanocellulose suspensions due to the high water content. The wettability of a paper is strongly influenced by its sizing, fillers, porosity, fibre 
density, fibre composition, and fibre preparation, as well as by any eventual surface treatment of paper [39].

The two types of nanocellulose were applied locally (edges, centrally located areas of paper) or the sheet as a whole was treated. The fully treated samples were used for analytical investigations.

Two application methods were tested: application by brush, a traditional method in paper conservation, and using a film applicator, based on the positive results obtained with adhesive processing during the preparation of remoistenable tissues [7]. The suspensions were always applied with vacuum in order to quickly reduce the high water content.

Because of their different properties the BNC and NFC had to be applied differently. For a complete application, the suspensions of BNC cellulose were applied with a wide Japanese brush radially from the centre of the sample. In case of a local treatment, the suspensions were applied by exactly coating only damaged areas, i.e., the damaged area was targeted precisely by a brush, similar to an application of an adhesive.

During the coating with NFC, only one application step was possible by using the brush from the left to the right due to the quick formation of fibre agglomerations. For the local application of NFC, the brush was placed onto the paper surface at an angle of $90^{\circ}$ to reduce the formation of those agglomerations.

The application with the film applicator was processed in the same way for BNC and NFC with a film thickness of 200 and $500 \mu \mathrm{m}$ (Fig. 2). Both types of nanocelluloses could be successfully applied on the samples. It was also possible to treat experimental tears at paper edges locally with the film applicator.

The use of specific concentrations (i.e., 0.5, 1, and 3\%) led to improvement of the application of NFC. Thus, suspensions with a lower solid content created a more uniform application and fewer agglomerations. However, the amount of applied NFC remained lower and the influence of water increased.

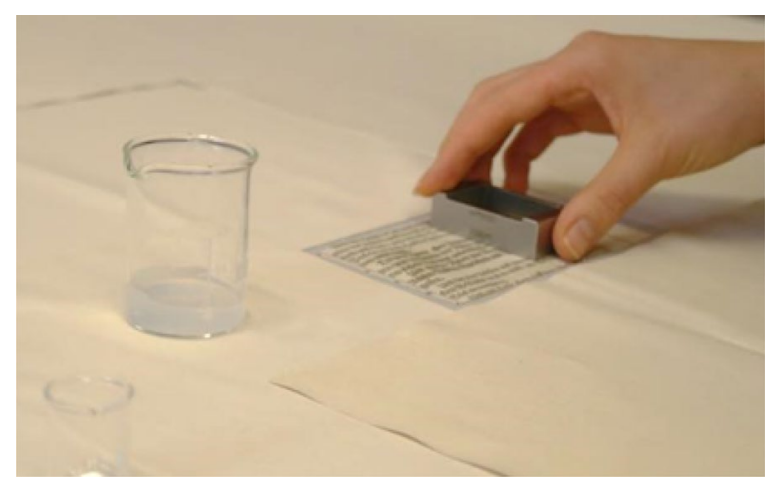

Fig. 2 The BNC is applied with the film applicator on a vacuum panel
Besides the pure nanocellulose suspensions, modified suspensions were applied on the historical model papers. Two approaches of modification or two variations of suspension with reduced water content and addition of adhesives were tested to see whether they could improve the treatment performance and the subsequent effects on the historical papers.

The approach chosen for reducing the water content was a solvent to exchange to other solvents, mainly ethanol. The high water retention of nanocellulose fibres renders a solvent exchange rather difficult [18]. In this study, it was possible to produce a suspension with a reduced water content of about $50 \%$. About $30-40 \%$ of water is, however, necessary to obtain a homogenous re-suspension of the nanocellulose for application.

Bacterial nanocellulose suspensions were (partially) freeze-dried prior to the addition of ethanol, whereas the NFC was used as is to perform a solvent exchange. Due to higher concentrations (2.5-3\%), NFC could be modified easier without losing characteristic properties. In contrast, the modification of the BNC suspension was more difficult, probably due to its very high water content. It lost its characteristics fairly quickly, i.e., its viscous suspension properties.

The addition of adhesives had a stabilizing effect on suspensions, especially with NFC. The handling of the suspensions and the application were facilitated and improved by the addition of SCMC and gelatin. In the modified suspensions and also during the application, no agglomerates were formed.

Hence, the suspensions with a lower water content can have positive as well as negative side effects. The addition of ethanol led to a faster absorption compared to pure water and enhanced aggregation, which renders the applicability more difficult. This is especially true for NFC. With regard to modified suspensions based on freeze-dried BNC, a loss of viscosity occurred. To some extent, fibre agglomerates were formed. Theses agglomerates caused an unsatisfactory irregular appearance on the papers' surfaces. The reason is an incomplete re-dispersion of BNC after freeze-drying, and thus this approach will require further study before it can be applied on paper. The addition of gelatin increases the overall film formation properties and stabilizes the suspensions. Still, the treated surface remains more sensitive to moisture and is relatively stickier than nanocellulose without gelatin.

In summary, it is possible to modify the nanocellulose suspension by varying the water content and adding adhesives, like gelatin and SCMC, in different concentrations. The suspension can be individually designed based on the actual sample to be treated. Parameters to be varied are fibre concentration, the type of solvent, or the 
addition of adhesives. The fibre concentration determines to a large extent the processing properties.

In the study, it was of great interest to determine the amount of material applied to paper because it strongly influences film formation, stabilizing effects, and also the visual and haptic properties. With increasing amounts of nanomaterial applied (in the range of 2-9\% nanocellulose), significant impacts on the paper, like haze and gloss, surface smoothing, and/or tension, can be observed.

On average, $18.72 \mathrm{mg}$ BNC (average weight gain: $1.79 \%$ ) and $12.53 \mathrm{mg}$ NFC (average weight gain: $1.20 \%$ ) were applied on the samples (size (width $\times$ length): $105 \times 130 \mathrm{~mm}$; average SD of applied nanocellulose amount: $2.67 \mathrm{mg}$ ). The minimum (BNC: $1.83 \mathrm{mg} / \mathrm{NFC}$ : $0.94 \mathrm{mg}$ ) and maximum (BNC: $70.38 \mathrm{mg} / 46.62 \mathrm{mg}$ ) values and the relatively high SD reflect the difficulty in applying a very constant amount of nanocellulose material, especially when a full coating was performed. The kind of nanocellulose, the properties of its suspensions, the wettability of sample papers, and the application method are influencing factors for the amount applied. Thus, using a film applicator had a positive effect on reproducibility for the entire application protocol. In addition, it was possible to apply more nanocellulose through multiple consecutive application steps. The total weight of the sample [rag paper (area: $9216 \mathrm{~mm}^{2}$ and applied nanocellulose)] could be increased up to $8 \%$ (NFC) or $9 \%$ (BNC) by using a brush in eight repeated application steps (Fig. 3). The use of the film applicator $(3 \times)$ achieved an even higher increase, especially for BNC (15\%).

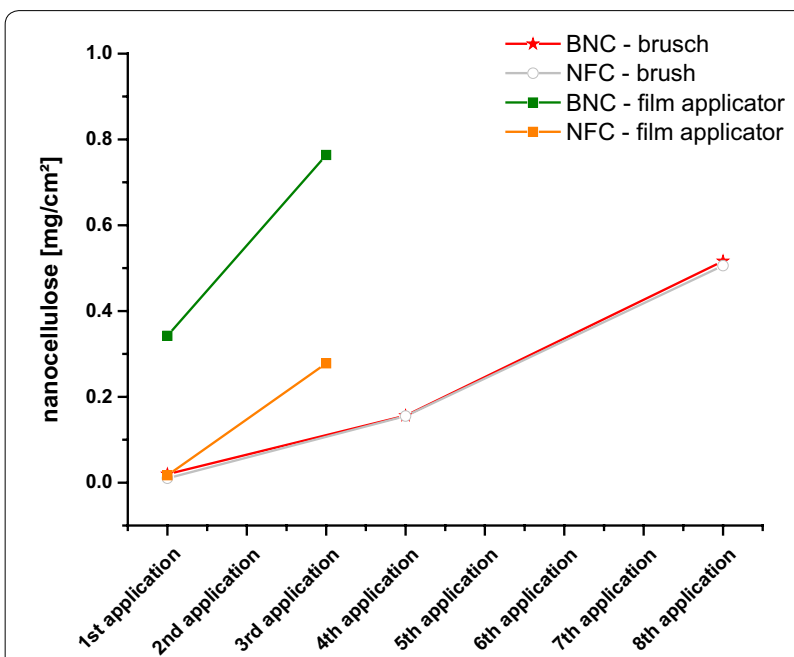

Fig. 3 Amount of nanocellulose remaining on rag paper (area: $92.16 \mathrm{~cm}^{2}$ ) when applied by brush and film applicator in consecutive treatments

\section{Visual and haptic properties}

The treatment generates a film at the papers' surface. The overall optical impression is closely related to the amount of nanocellulose applied: From approximately $2 \%$ nanocellulose, slight (BNC) or very slight (NFC) hazes are clearly visible and become much more apparent with increasing amounts. Thus, letters appear more veiled with $8 \%$ NFC or $15 \%$ BNC. The signs of BNC look shinier when a higher amount is applied, whereas the films of NFC occur more as matt, white hazes without gloss. This is an important advantage of NFC. Besides the amount applied, the gloss with BNC is increased by using the film applicator.

After application of both nanocellulose types in a concentration of 0.5 and $1 \%$, the brightness of blank areas of book paper without wood pulp (V) was not changed before and after aging (6 days). The fluctuation measured (approximately 1\%) is within the standard deviation (0.6-1.8\%).

Printed areas on paper are only slightly influenced by the nanofibers that form films on the paper surface as they homogenously adhere to the surface. So the treated areas are hardly or not at all visible, whereas the fibrous structure of Japanese paper visually structures the surface-especially on letters-and changes the paper surface noticeably [24]. Hence, nanocellulose is superior in that respect compared to classical treatment options; especially in the case of closely written papers.

The influence on haptic properties (structure of surface, flexibility, tension, thickness) is very small. It is again closely related to the amount of nanocellulose applied. The risk for tension in the paper may increase with increasing amounts of nanocellulose. In addition, tension is affected by large amounts of water applied during the treatment [40]. A change of the surface is noticeable starting with a weight gain of approximately $9 \%$ for BNC and 5 or $8 \%$ for NFC.

In summary, it can be stated that the treated sample papers are influenced optically and haptically by the films that have been created; however, the impact is very minor compared to traditional stabilizing methods.

\section{Microscopy}

On the microscopic level (SEM/AFM), it is also visible that more or less pronounced films and fibre networks emerge along the original paper fibres. The fibres of paper are surrounded by the BNC or NFC fibres, and the neighbouring pores are filled partly or completely. Additionally, few single fibres or fibre agglomerates are visible.

The films of nanocellulose differ by their characteristic material and suspension properties. The areas treated with $\mathrm{BNC}$ are clearly visible, and the films are uniformly 
structured due to the relatively consistent fibre diameter, as well as by the smooth and homogenous fibril bundles (Figs. 4 left, 5 left). They have a smoother, shinier surface and a transparent appearance. In contrast, the borderlines of treatment with NFC are relatively vague, and the films are structured heterogeneously (Figs. 4 right, 5 right). Thicker fibre bundles are split into thinner single fibres during NFC production and therefore they have a more heterogeneous fibre structure. As a result, the film surfaces appear more rough and irregular; for this reason, they have a matt appearance.

These observations are closely related to the surface structure of paper and to the application. The fibre structure of paper influences the formation of films noticeably whereas at the same time the original structures of historical papers remain intact and recognizable under the nanocellulose films. Apparently the adherent surface films of nanocellulose enable the stabilization of historical papers and therefore also the treatment of mechanical damage with or without adhesive additives. The precise connection process of fibres and films on paper has not been subject of analyses however it can be safely assumed that hydrogen bonds constitute a significant portion of bonding forces [41, 42].

After cyclic aging $\left(80-30{ }^{\circ} \mathrm{C}\right.$ cycles for $\left.6 \mathrm{~h}\right)$ of treated Whatman no. 1 paper, no significant changes visible under the microscope could be determined (SEM/light microscope). No breaks, cracks, or tears in treated areas, no increased tensions, and no material failures were induced. Therefore, local stabilizing effects of tears remain intact also after an accelerated aging of 2-3 weeks (336 or $504 \mathrm{~h})$.
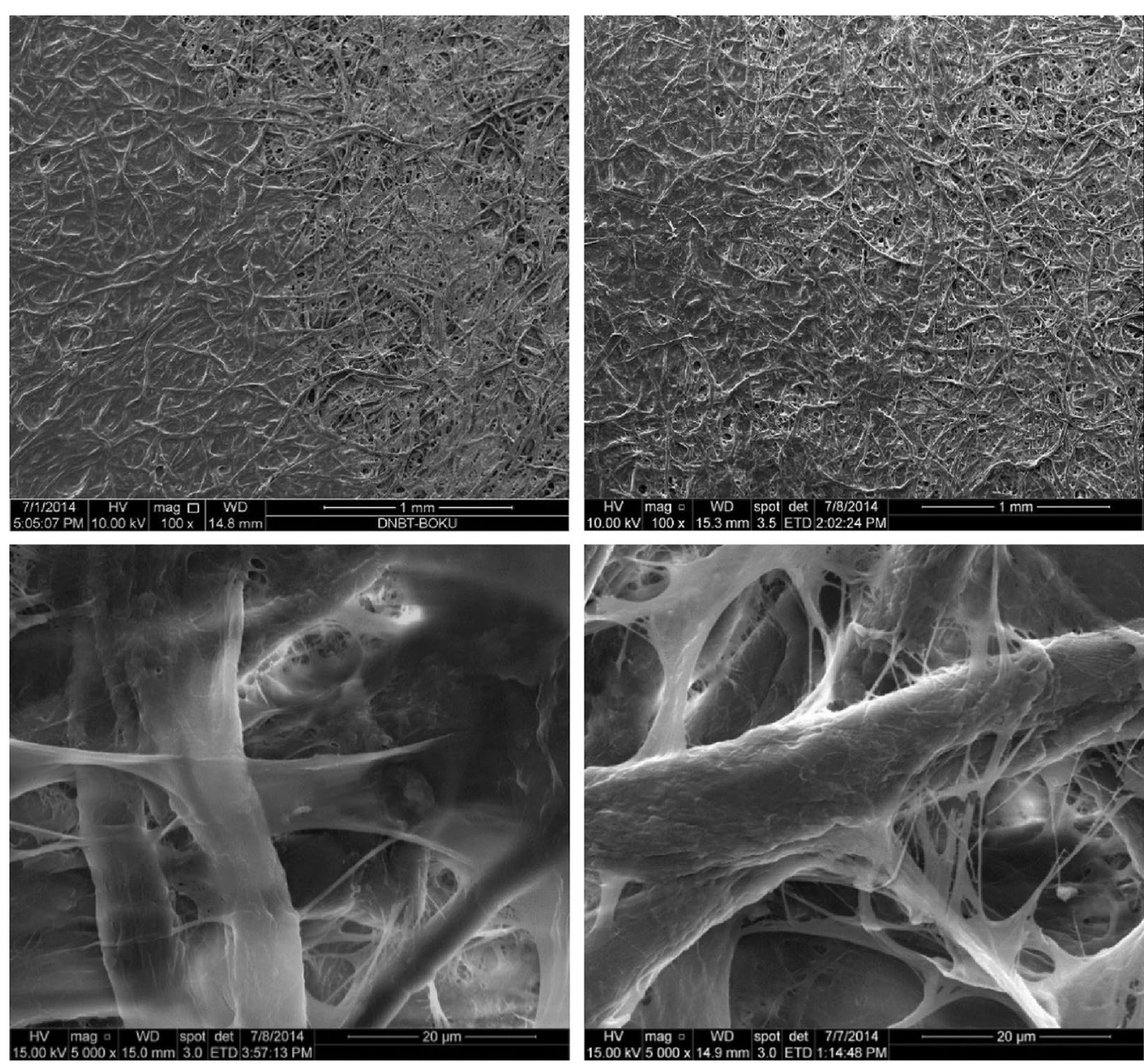

Fig. 4 Left: Whatman no. 1 paper treated with BNC (top: $\times 100$ magnification; bottom: $\times 5000$ magnification). A clear borderline between the treated (left) and the untreated (right) areas is visible. The SEM picture (bottom) shows clearly that original structures of papers (thicker fibres) remain intact and recognizable. Right: Whatman no. 1 paper treated with NFC (top: $\times 100$ magnification; bottom: $\times 5000$ magnification). The borderline between the treated (left) and untreated (right) areas is not as clear as with BNC. Also for BNC the structures of the original paper (thicker fibres) remains intact and recognizable 

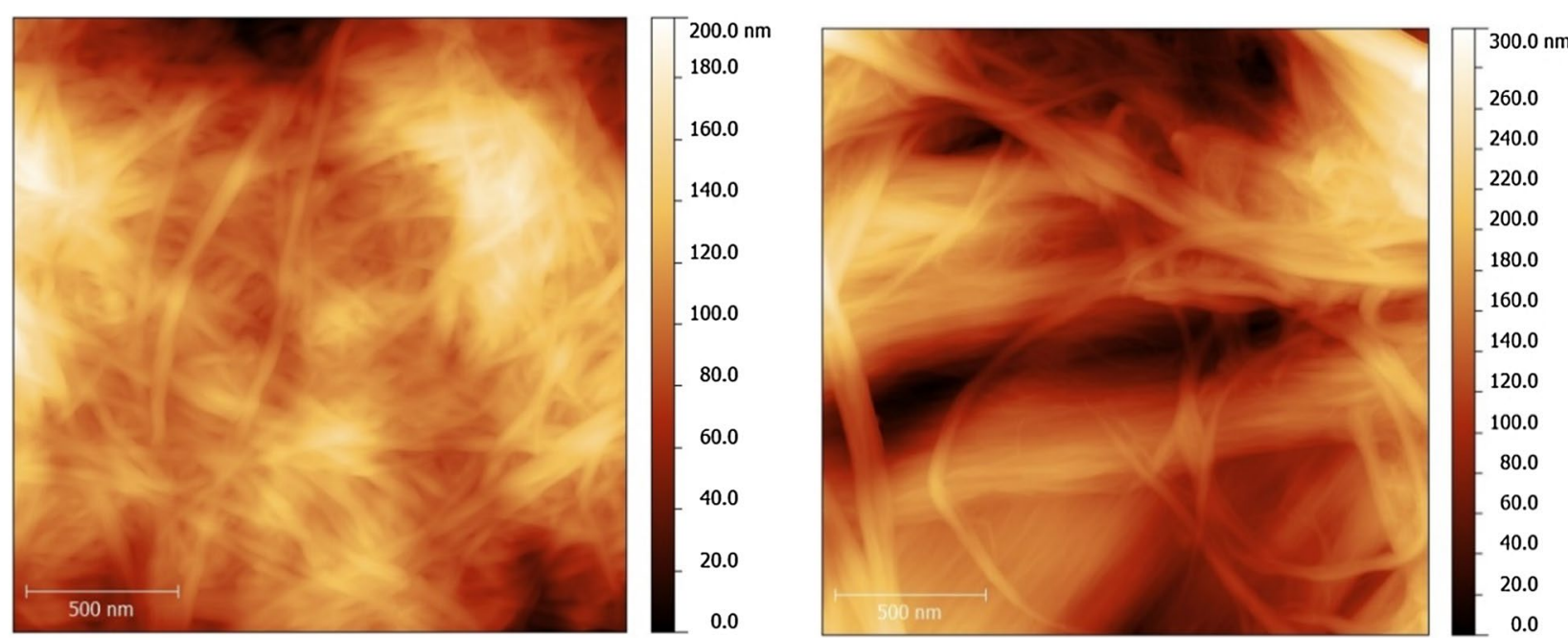

Fig. 5 AFM images. Left: The film of BNC is uniformly structured by the relatively consistent fibre diameter. Right: In contrast, the film of NFC is structured inhomogeneously different fibre diameter and fibres bundles are visible

\section{Paper stability and accelerated aging}

In long-span measurements, different parameters can be calculated with measured tensile strength [21,43]; Fig. 6 shows the tensile index [tensile strength $(\mathrm{N} / \mathrm{m}) /$ basis weight of paper $\left.\left(\mathrm{g} / \mathrm{m}^{2}\right)\right]$ of long-span measurements. The values of breaking force and breaking length that were calculated by zero-span measurements are identical in trends and in intensities. The breaking force is presented in Fig. 7.

The tensile strengths of treated samples differ depending on the kind of paper, the condition before and after aging ( 6 days), and the kind of nanocellulose suspension applied. The values are affected by inhomogeneous properties of paper, so that values for aged rag samples (II) are higher than those of unaged samples, although both kinds of samples have been treated with the same suspension. The rag paper (II) used is a very inhomogeneous paper; with high standard deviation also with regard to paper thickness. This inhomogeneity significantly influences the tested strength properties and is evidenced by high overall standard deviations (Fig. 6).

Before aging, the tensile index and the breaking force of samples did not indicate any linear and clear development (Figs. 6, 7). In zero-span, the results of breaking force are higher for the treatment with pure BNC with a fibre length of 0.1 and $1 \mathrm{~mm}$ (from 0.350 to $0.450 \mathrm{~kg}$ higher), but not for a length of $0.25 \mathrm{~mm}(0.665 \mathrm{~kg}$ lower). This indicates the difficulty of applying a constant level of nanocellulose. All samples treated with NFC show an increased value in breaking force that fluctuates strongly in its intensity.

Most values within the long-span measurements dropped slightly, except for rag paper samples, due to the accelerated aging (6 days), so that the aging processes exerts a small influence on the strength properties of sample papers. Nevertheless, the tensile index values of some sample variations are higher compared to the aged reference.

In contrast, the decrease of zero-span tensile strength of treated samples after aging ( 6 days) was higher than that of untreated reference samples. This indicates that the treatments or the high moisture content of suspensions have an overall effect on the (zero-span) tensile strength of samples. The increasing and excessive moisture induces plasticizing effects in paper and thus reduces the tensile strength of paper [44]. Furthermore, Moropoulou and Zervos stated that the decrease of strength properties, and especially the tensile strength, is not only caused by the reduction of sizing within water-based treatments; additionally, further mechanical influences must also be taken into consideration, such as negative effects on the formation of intra- or intermolecular bonds by moistening and drying. Moreover, they rightly bring out inhomogeneous or permanent moistening and subsequent drying processes within which different swelling and shrinking processes take place simultaneously in the paper. It is conceivable that fibres slip out of or are pulled out of the paper structure and in such manner the paper strength will be negatively influenced [44].

A continuous positive development of tensile strength can be observed for the samples of both types of nanocellulose with the addition of gelatin. Probably most of the stabilizing effect must be attributed to the surface film of gelatin; however, this statement has to be treated with caution, as a reference sample treated with pure gelatin was not available. 


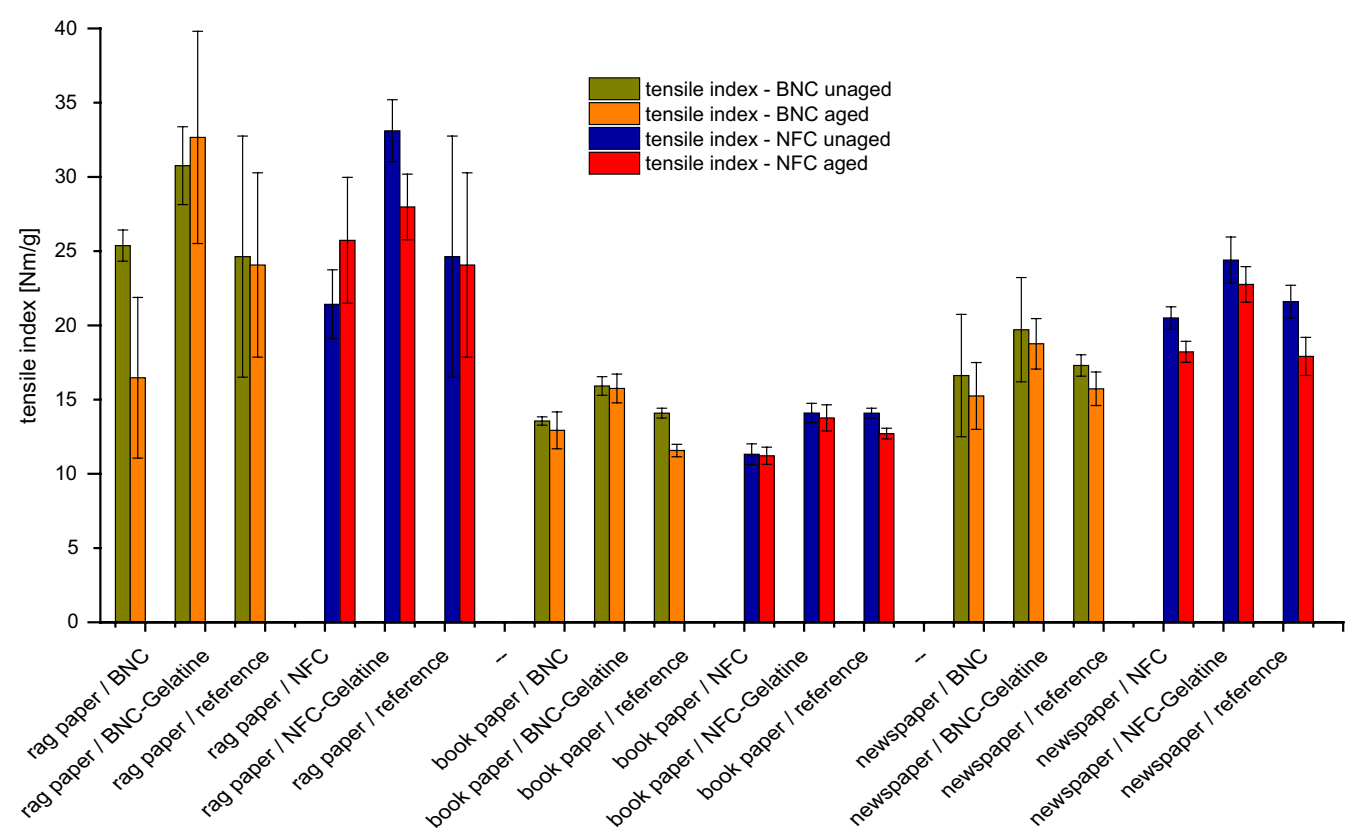

Fig. 6 Samples treated with BNC and NFC-tensile index of long-span before and after aging (6 days)

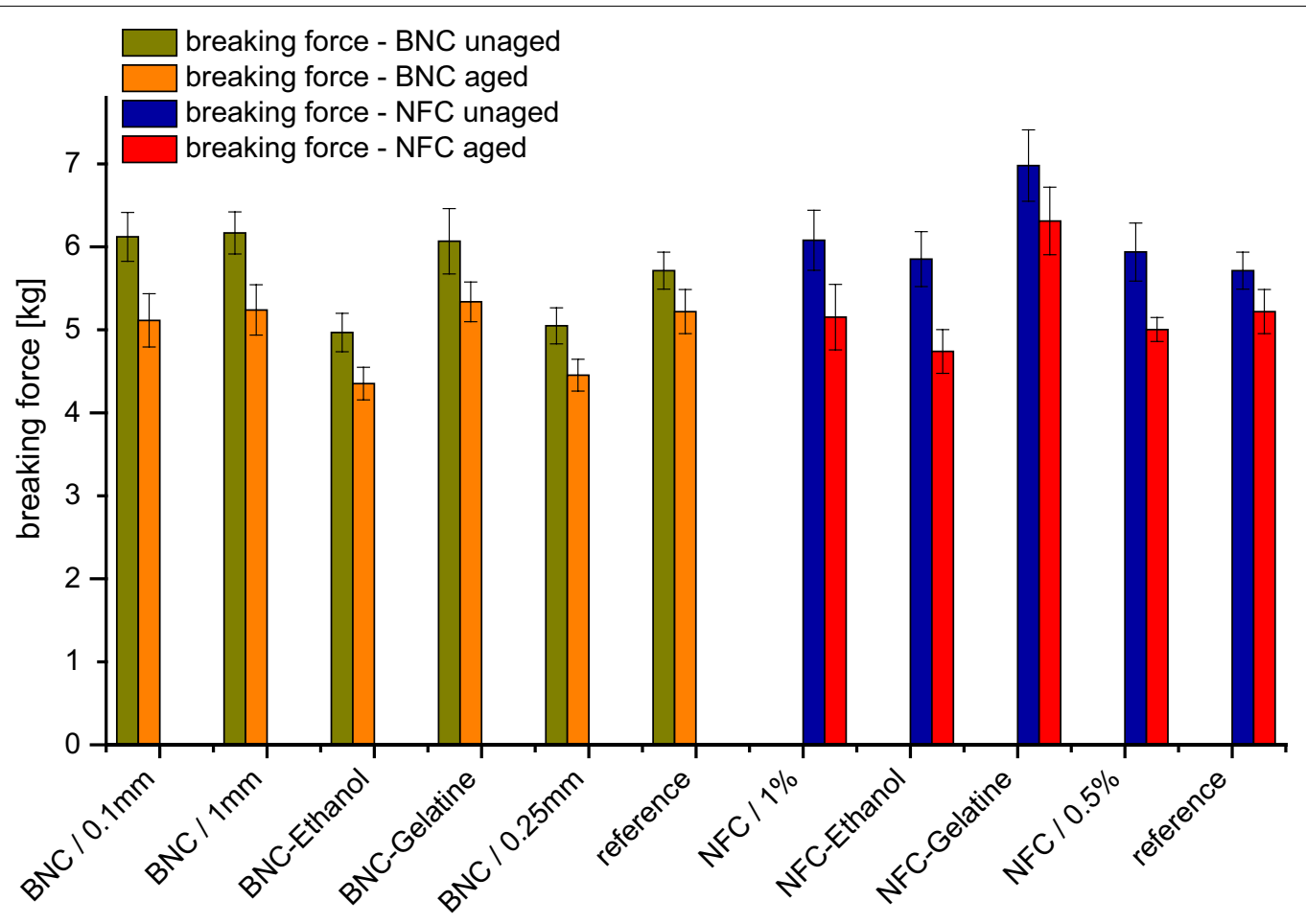

Fig. 7 Newspaper (1946) treated with BNC and NFC-measurement results of zero-span before and after aging (6 days)

Within the scope of strength measurements, a consistent rise of tensile index or breaking force was expected in order to be able to show the stabilizing effects of BNC and NFC. The data obtained from long- and zero-span measurements (Figs. 6, 7) are not very conclusive. After different treatments and accelerated aging ( 6 days), data 
scattered without providing consistent trends. Besides the inhomogeneity of papers (varying also in paper thickness), which often causes high standard deviations in methods that only investigate a rather small sample size, the overall mass of nanocellulosic material added is comparably small. The results show that the application plays an important role for the strength properties, because different amounts of suspension and fibre material were applied (BNC 0.1, 1, $0.25 \mathrm{~mm}$; Fig. 7), which affected the paper strength. The increase of tensile strength is also slightly affected by the fibre concentration of NFC (0.5 or 1\%; Fig. 7). Overall, the amount of nanocellulose material is the decisive factor for a verifiable influence on the tensile strength. Brodin et al. quoted from a study by Syverud and Stenius [45]: "Therefore, introduction of a strong CNF layer on the surface of a base paper may have only minor influence on the tensile index. For example, coating with $8 \mathrm{~g} \mathrm{CNF} / \mathrm{m}^{2}$ increased the tensile index from 35 to $40 \mathrm{Nm} / \mathrm{g}$ ", which showed that a high amount is necessary [21]. In the named investigation, the amount of the applied nanocellulose material is for BNC five- to sixfold and for NFC eight- to ninefold higher than in the presented study. So the stabilizing effect of the thin nanocellulose film disappears in the values of the comparably thick paper, and hence has no influence on the paper strength. In addition, the high standard deviations of mechanical tests in general were not very obliging when looking at effects generated by a tiny but strong film at the paper surface.

\section{Cellulose integrity after aging}

In order to analyse the aging characteristics of the nanocellulose and their effects on the molecular level, a part of the treated paper samples and isolated films of nanocelluoses were analysed after artificial aging in a closed vessel system (ASTM standard D6819-02e3 [31, 32]) for 6 or 20 days. For the samples, the molar mass distribution and the carbonyl groups generated during aging were analysed $[34,35]$. In this setup, the complete sample (10-20 mg total) was analysed after a carbonyl group derivatization step followed by dissolution and SEC-MALLS analysis. The BNC and NFC were thus analysed as part of the whole sample. However, the concentration of BNC and NFC respectively is clearly below $10 \%$ and hence affects the overall molar mass only to a minor extent. In general, a standard deviation of $15 \%$ has to be expected for the samples analysed, as they are either very high in molar mass (BNC) or not easy to dissolve (book paper sample and newsprint). In addition, the rag paper sample showed an exceptionally high inhomogeneity.

The unaged bacterial cellulose film (analysed alone without any paper substrate) has naturally a much higher average molecular weight $(790.4-926.5 \mathrm{~kg} / \mathrm{mol})$ than the unaged NFC (around $243.2 \mathrm{~kg} / \mathrm{mol}$ ), which corresponds to data of previous studies $[11,12]$.

Bacterial nanocellulose showed a slightly lower $\mathrm{Mw}$ value only after 6 days of aging, declining from 790.4 to $718 \mathrm{~kg} /$ mol (Fig. 8). For a second aged sample, the $\mathrm{Mw}$ value was $1053 \mathrm{~kg} / \mathrm{mol}$, above the unaged Mw $(905.4 \mathrm{~kg} / \mathrm{mol})$. This behaviour has to be attributed to the difficulties in analysing such high molar mass samples (see above), but it demonstrates the typical stability of BNC during aging. In contrast, NFC decreased its Mw from 246.3 to $209.4 \mathrm{~kg} /$ mol after aging for 6 days, as it is more vulnerable to overall degradation due to the treatment history during fibrillation.

The bacterial cellulose showed more carbonyl groups in the low-molecular weight area than expected from the number of reducing ends in this region from the pure
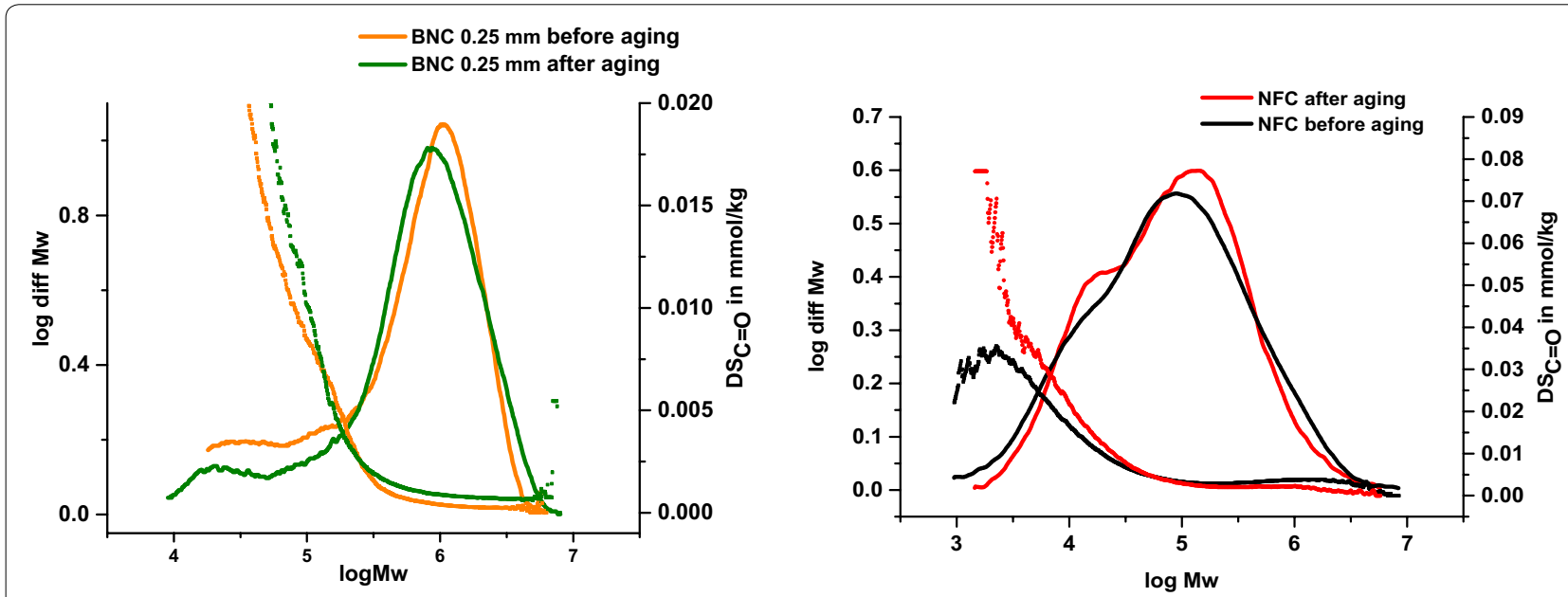

Fig. 8 Distribution of molecular weight and carbonyl groups of pure nanocellulose films (left BNC and right NFC) 
cellulose part. Typically, purified BNC ranges around $2-5 \mu \mathrm{mol} / \mathrm{g}$. This large share of carbonyls could be due to the presence of short-chain CMCs (DP 400), which are added as modifier in the production of this particular BNC. The amount of carbonyl groups of bacterial cellulose increased from 22 to $33 \mu \mathrm{mol} / \mathrm{g}$ after aging (6 days). In contrast, the carbonyl groups of nanofibrillated cellulose slightly decreased from 54 to $49 \mu \mathrm{mol} / \mathrm{g}$ after aging (6 days). Therefore, the bacterial and the nanofibrillated cellulose are relatively inert and stable materials, and show no or very minor degradative changes during the process of artificial aging.

The rag paper (II) yielded the typical high stability even after 20 days of accelerated aging (Fig. 9 left). Except for an outlier for the unaged rag sample because of its inhomogeneity, the data are within a very similar range, and no negative effect due to the BNC treatment is observed. The same is true for the treated book paper (Fig. 9 left). Here, only the BNC with gelatin yields a close to significant loss in molar mass after aging (20 days).

For all rag samples, the number of carbonyl group contents is considerably lower after aging (20 days). Usually the opposite is true due to a decrease in molar mass and the simultaneous generation of new reducing ends. As the cellulose degradation is not very pronounced, this effect is rather minor. We suspect that, after aging, a portion of low molar mass compounds is washed out during sample pretreatment prior to analysis, carrying a significant number of carbonyls and hence leading to the observed drop. For book paper (IV), the values of carbonyl groups stay in a similar range $(50-60 \mu \mathrm{mol} / \mathrm{g})$ before and after aging for 20 days. The unaged reference sample of book paper (IV) is no representative benchmark concerning the carbonyl group content-its value is $101 \mu \mathrm{mol} / \mathrm{g}$, which is exceptionally high and which we lack an explanation for.

The newsprint paper from 1877 was treated with $\mathrm{BNC}$; its values of molar mass $(\mathrm{Mw})$ ranged between 120 and $160 \mathrm{~kg} / \mathrm{mol}$ in unaged condition (Fig. 9, right). After aging for 6 days, the values decrease to around $100 \mathrm{~kg} / \mathrm{mol}$, hence slightly oscillating around the critical value of $\mathrm{Mw}$ of $100 \mathrm{~kg} / \mathrm{mol}$ [43]. The paper is endogenously strongly degraded and very susceptible to mechanical stress, also evident by mechanically damaged edges.

Cellulose in the newsprint reference samples was not degraded to a large extent after 6 days of aging (Fig. 9, right). For newsprint of 1877 the treatment with BNC$0.25 \mathrm{~mm}$ showed similar results compared to the nontreated reference, whereas for newsprint of 1946 the similar values resulted from the treatment with BNCEthanol. Interestingly, the presence of gelatin had a negative effect, which is consistent with the other newsprint sample (Fig. 9 right) and the book paper (Fig. 9 left).

For the treatment with NFC suspensions, the behaviour is not so much different from the BNC variant (Fig. 10). Degradation is comparable to the non-treated reference, and the effect of gelatin is not sticking out as pronounced as for the BNC treatments; only in case of the newsprint from 1946 is the MW is slightly lower compared to the reference (Fig. 10 right).

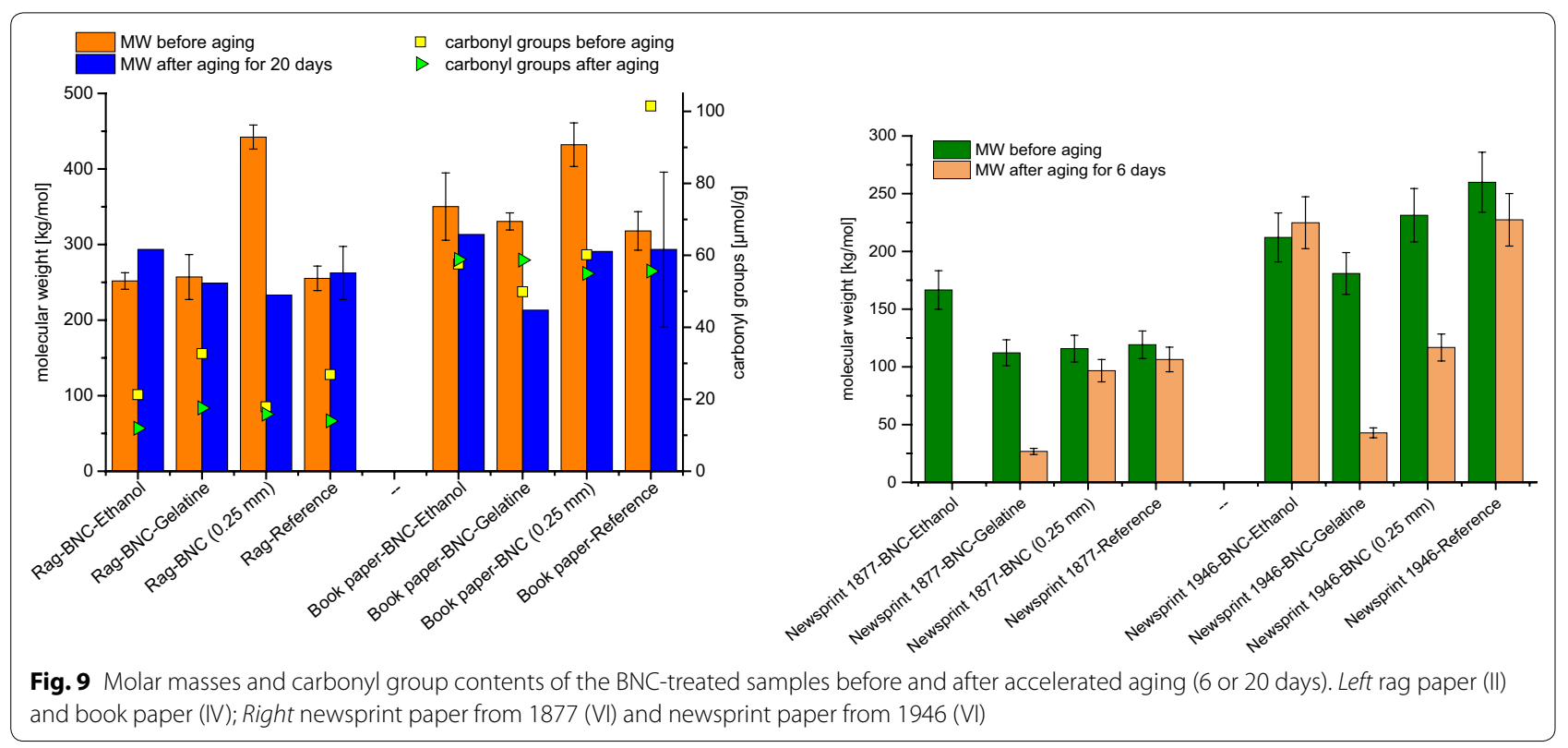



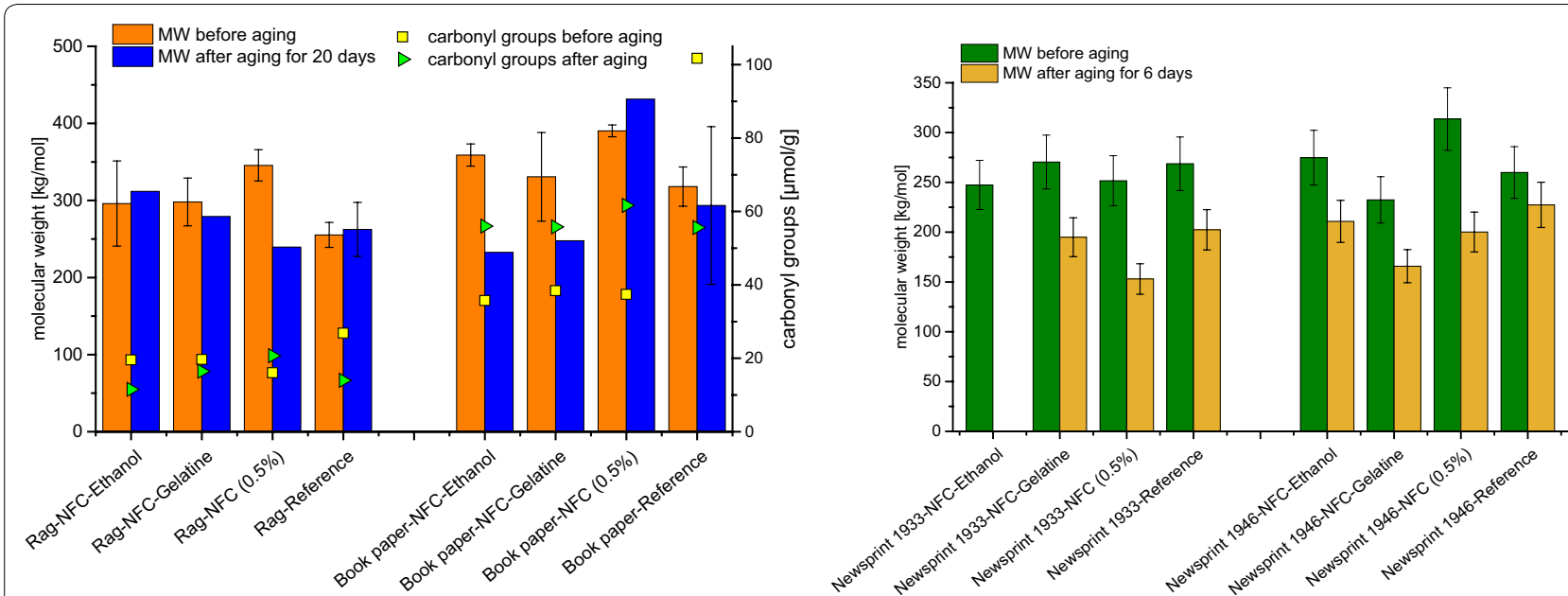

Fig. 10 Molar masses and carbonyl group contents of NFC-treated samples before and after accelerated aging (6 or 20 days). Left Rag paper (II) and book paper (IV); right newsprint paper from 1933 (VI) and newsprint paper from 1946 (VI)

In summary, considering the paper samples that show a rather large standard deviation due to inhomogeneity and solubility issues, no negative effect on cellulose integrity could be observed after accelerated aging (6 or 20 days). The effect of applying gelatin together with $\mathrm{BNC}$ or NFC suspension needs further investigation to avoid possible negative effects.

\section{Results of processing and application}

The effects of processing also differ individually depending on the kind of nanocellulose, on the type of suspension, and on the application area or the paper properties. The application of BNC as a transparent, viscous suspension $(0.5 \%)$ can be carried out well and evenly. The suspension can be applied to paper locally or entirely, once or several times. The homogeneity of application can be monitored in an oblique light. The examined varying fibre lengths have no influence on application properties. All in all, the processing of BNC suspension reminds us of the viscous suspension of cellulose ethers.

The white viscous suspensions of NFC have in general a fibrous or rougher appearance than BNC suspensions. It probably results from the white colour and the heterogeneous structure of fibres, as well as from the stronger tendency to form fibre aggregates. Because of this tendency and because of the properties of this suspensions, a complete application is difficult. Only a specific application by brush is possible; otherwise, the applied fibres will be pushed together into larger aggregates on the surface. As a result, only little fibre material is applied which is unevenly distributed on the paper surface. Until now, the regularity of the applied layers cannot be controlled during treatment. The treatment result can be significantly improved by the addition of an adhesive that stabilizes the suspension. Significantly fewer aggregates are formed by a local treatment depending on the area and the paper structure. Variations of local application methods facilitate a further down scaling-for example, by using a brush placed onto the paper surface at an angle of $90^{\circ}$. Generally, the aggregates that are formed in connection with the entire or local application after drying are in optical terms surprisingly of little importance. But they influence the formation of a closed, homogeneous surface film when the whole surface has to be treated.

In both cases, the stroke or dab by brush and the use of a film applicator have proven as appropriate methods. Satisfactory and consistent results of application and good, promising stabilizing results were achieved.

Independent of the nanocellulose suspension and the size of treatment area, two phenomena could be observed that were caused by the high moisture content of the suspensions. The heterogeneous humidification and drying of samples during the treatments resulted in visually striking wet-dry interfaces and in paper tensions. Due to an inhomogeneous distribution of moisture in paper and/ or an uneven drying, dissolved substances accumulate in interfaces between dry and wet areas where the excessive water evaporates $[40,46]$. The wet-dry interfaces become visible as yellow to brown coloured marks directly after treatment or after accelerated aging; they are widely discussed in scientific literature [5, 40, 46]. Furthermore, mechanical forces are caused by the inhomogeneous or locally limited influence of water, which has an impact on the paper structure and cellulose fibres-meaning the mechanical properties of the paper.

Both phenomena are considered negative side effects in paper conservation. The wet-dry interfaces disturb the 
aesthetic appearance of an object [47]. Moreover, in areas that were exposed to water, chemical modifications at the molecular level are discussed that are associated with radical formation and oxidative degradative reactions $[47,48]$. The locally limited influence of water causes different mechanical burdens of the fibre structure, which can accelerate the process of cellulose degradation and can change the mechanical and/or aging properties of the paper [40]. The exact reaction mechanisms of the development and the effects of wet-dry interfaces at the molecular level are still not entirely clear. Henniges and Potthast [46] observed no significant increase of carbonyl groups and hence the hydroxyl groups were not subjected to pronounced oxidative reactions. Because of the aesthetic influence and the described risks, which are difficult to calculate, it is mostly recommended in conservation literature to avoid local treatment with a high proportion of water. If that is not possible, the risk should be minimized to the furthest extent possible by decisive measures [40, 47]. With regard to some open questions related to the application of BNC and NFC as stabilizing materials, the subject addressed in this paper can serve as building block for future research.

\section{Conclusion}

The study presented shows that stabilization of mechanically damaged papers is possible by direct application of BNC or NFC. Damaged areas are consolidated, cracks are closed, and small losses are coated with a higher amount of applied nanocellulose (Fig. 11).
The properties of processing and the results of application of BNC and NFC are comparable with an adhesive application. They can be applied by brush or a film applicator in a promising approach. The possibilities of suspension variation probably provide future opportunities.

Formed films on the paper surface are visible and noticeable depending on the applied quantity; they induce low optical and haptic changes. Especially compared to traditional stabilizing methods, the optical and haptic influences are very low. During accelerated aging in closed vessels (6 or 20 days), changes occurring are not different from the untreated references. Thus, the treatments of historical paper with BNC or NFC do not cause negative side effects in the long term.

The stabilizing effects of nanocellulose materials are primarily noticeable in the case of a local treatment of mechanical damages. Comparable with adhesive treatments, the increase of the physical paper strengths and also the physical consolidation of paper are difficult to prove by mechanical analysis. However, for the first time, the treatment of mechanical damage and the consolidation of weakened paper areas can be realized by application of nanocellulose suspension without an additional adhesive-an innovative approach for paper stabilization eliminating side effects caused by additives. The damaged paper structure can exclusively be stabilized with a pure material that has strong similarities to the original material "cellulose" in structure and characteristics and
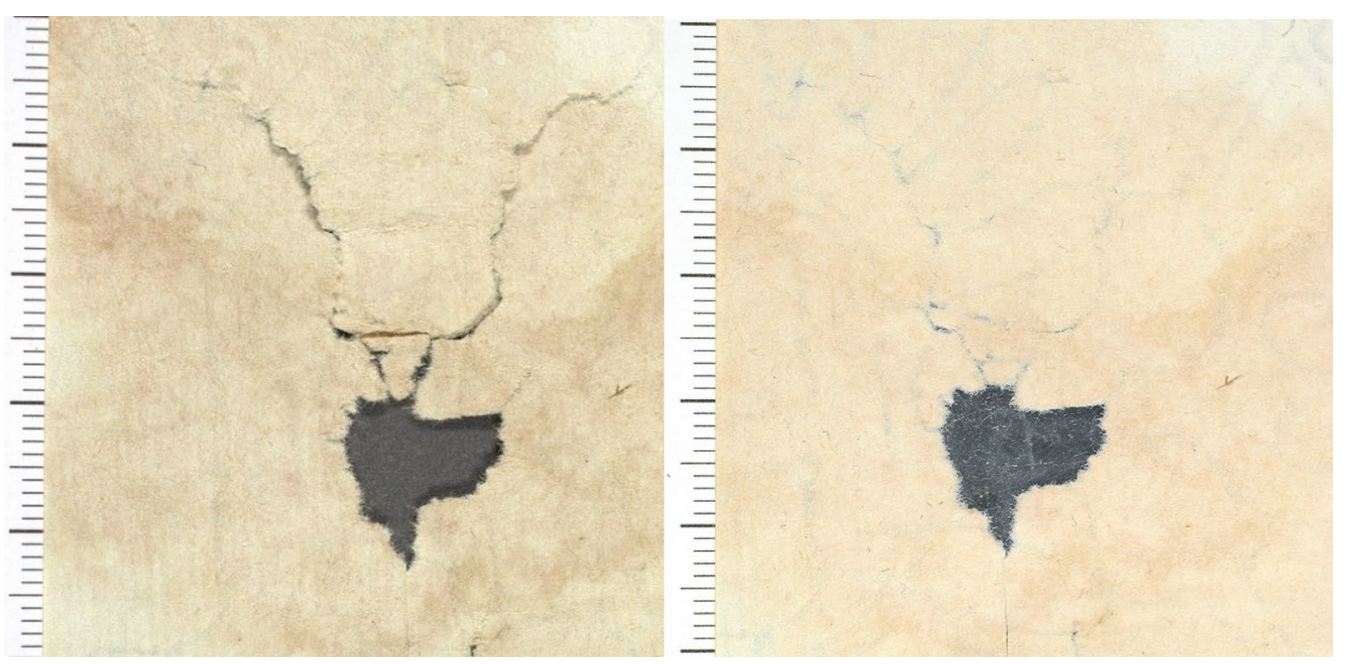

Fig. 11 The mechanical damages (cracks and losses; left) are closed and coated after a direct application of nanocellulose (right). The damaged paper is consolidated and stabilized 
which has very good aging properties. Hence, the BNC, as well as the NFC, are promising materials for paper stabilization.

\section{Authors' contributions}

LV conducted the practical work, evaluated the data and wrote the major parts of the manuscript. KA performed the microscopic analysis, was involved in SEC analysis and wrote part of the manuscript. UH designed and supervised the paper conservation part of the study and helped with preparation of the manuscript. WGA provided expertise with nano-cellulose handling and helped with data interpretation. AP designed the scientific part and coordinated the study, evaluated/interpreted data and wrote part of the manuscript. All authors read and approved the final manuscript.

\section{Author details \\ ${ }^{1}$ Department of Conservation and Special Collections, Herzogin Anna Amalia Bibliothek, Platz der Demokratie 1, 99423 Weimar, Germany. ${ }^{2}$ Division of Chemistry of Renewables, Department of Chemistry, University of Natural Resources and Life Sciences (BOKU), Konrad-Lorenz-Strasse 24, 3430 Tulln, Austria. ${ }^{3}$ Faculty of Architecture, Engineering and Conservation, University of Applied Sciences and Arts, Tappenstraße 55, 31134 Hildesheim, Germany. ${ }^{4}$ Institute of Wood Technology and Renewable Materials, University of Natural Resources and Life Sciences (BOKU), Konrad-Lorenz-Strasse 24, 3430 Tulln, Austria.}

\section{Acknowledgements}

We would like to thank the Institute for Paper-, Pulp- and Fibre Technology (TU Graz, Austria) and the Institute of Wood Technology and Renewable Materials for their support with testing and providing nanofibrillated cellulose samples. We are grateful to the Herzogin Anna Amalia Library, Weimar, Germany, and the research library Gotha, Germany, for supporting this project. The financial support by the COST action 1205 for an STSM (LV) is gratefully acknowledged.

\section{Competing interests}

The authors declare that they have no competing interests.

\section{Publisher's Note}

Springer Nature remains neutral with regard to jurisdictional claims in published maps and institutional affiliations.

Received: 16 December 2016 Accepted: 11 April 2017

Published online: 15 June 2017

\section{References}

1. Strlič M, Grossi CM, Dillon C, Bell N, Fouseki K, Brimblecombe P, et al. Damage function for historic paper. Part I: fitness for use. heritage. Science. 2015;3(33):1-12

2. van Velzen B. A morphlogy of the tear: a first approach towards a general terminology. PapierRestaurierung. 2006;7(2):13-6.

3. Völkel L, Reiche M, Hähner U, Rittmeier B. Arbeitsbrief für eine Rissschließung; Internes Dokument-Studiengang Konservierung und Restaurierung von Schriftgut. Hildesheim: Buch und Graphik; 2015.

4. Wächter $O$. Restaurierung und Erhaltung von Büchern, Archivalien und Graphiken: Mit Berücksichtigung des Kulturgüterschutzes laut Haager Konvention von 1954 3. verbesserte ed. Graz: Hermann Böhlaus Nachfolge; 1982.

5. Wächter W. Bücher erhalten, pflegen und restaurieren. Stuttgart: Hauswedell \& Co.; 1997.

6. Schweidler $\mathrm{M}$. The restoration of engravings, drawings, books and other works on paper: translated, edited, and with an appendix by roy perskinson. Los Angeles: Getty Publications: 2006.

7. Titus S, Schneller R, Huhsmann E, Hähner U, Banik G. Stabilising local areas of loss in iron gall ink copy documents from the Savigny estate. Restaurator. 2009;30(1):16-50.

8. Hofmann C, Hartl A, Ahn K, Faerber I, Henniges U, Potthast A. Studies on the conservation of verdigris on paper. Restaurator. 2015;36(2):147-82.
9. Völkel L. Überblick zum Einsatz beschichteter Stabilisierungspapiere in der Papierrestaurierung [Bachelor-Thesis]. Hildesheim: HAWK-Hochschule für angewandte Wissenschaft und Kunst; 2012.

10. Klemm D, Schumann D, Kramer F, Heßler N, Hornung M, Schmauder HP, Marsch S. Nanocelluloses as innovative polymers in research and application. In: Klemm D, editor. Polysaccharides II. Berlin: Springer; 2006. p. 49-96.

11. Siró I, Plackett D. Microfibrillated cellulose and new nanocomposite materials: a review. Cellulose. 2010;17(3):459-94.

12. Klemm D, Kramer F, Moritz S, Lindström T, Ankerfors M, Gray D, et al. Nanocellulosen: eine neue Familie naturbasierter Materialien. Angew Chem. 2011;123(24):5550-80.

13. Klemm D, Schumann D, Kramer F, Heßler N, Koth D, Sultanova B. Nanocellulose materials-different cellulose, different functionality. Macromol Symp. 2009;280(1):60-71.

14. Seifert M. Modifizierung der Struktur von Bakteriencellulose durch die Zusammenstellung des Nährmediums bei der Kultivierung von Acetobacter xylinum [Dissertation]. Jena: Friedrich-Schiller-Universität; 2004.

15. Wesarg F. Herstellung funktioneller Hybride auf Basis von bakteriell synthetisierter Nanocellulose [Dissertation]. Jena: Friedrich-SchillerUniversität; 2013.

16. Heßler N. Bakterielle Nanocellulose: Struktur- und Formdesign während der Biosynthese [Dissertation]. Jena: Friedrich-Schiller-Universität; 2008.

17. Köster A, Förter-Barth U, Herrmann M, Schweppe R, Teipel U. Herstellung von Nanocellulose durch mechanischen Aufschluss. Chem Ing Tec. 2014;86(3):302-6.

18. Dufresne A. Nanocellulose: From nature to high performance tailored materials. Berlin: de Gruyter; 2012.

19. Missoum K, Belgacem M, Bras J. Nanofibrillated cellulose surface modification: a review. Materials. 2013;6(5):1745-66.

20. Rezayati Charani P, Dehghani-Firouzabadi M, Afra E, Blademo $\AA$, Naderi A, Lindström T. Production of microfibrillated cellulose from unbleached kraft pulp of Kenaf and Scotch Pine and its effect on the properties of hardwood kraft: microfibrillated cellulose paper. Cellulose. 2013;20(5):2559-67.

21. Brodin FW, Gregersen ØW, Syverud K. Cellulose nanofibrils: challenges and possibilities as a paper additive or coating material-a review. Nord Pulp Paper Res J. 2014;29(1):156-66.

22. Yousefi H, Faezipour M, Hedjazi S, Mousavi MM, Azusa Y, Heidari AH. Comparative study of paper and nanopaper properties prepared from bacterial cellulose nanofibers and fibers/ground cellulose nanofibers of canola straw. Ind Crops Prod. 2013:43:732-7.

23. Santos SM, Carbajo JM, Gómez N, Quintana E, Ladero M, Sànchez A, et al. Use of bacterial cellulose in degraded paper restoration. Part I: application on model papers. J Mater Sci. 2016;51(3):1541-52.

24. Santos SM, Carbajo JM, Gómez N, Quintana E, Ladero M, Sànchez A, et al. Use of bacterial cellulose in degraded paper restoration. Part II: application on real samples. J Mater Sci. 2016;51(3):1553-61.

25. Seger A, Kochendörfer P. Bacterial cellulose: a new material in paper conservation. In: Tagungsband zum XIIIth Congress Berlin 2015. Berlin: Laserline; 2015. p. 73.

26. Okayama T, Kadoya C, Kose R, Seki M, Sonod N. A new technique for strengthening degraded paper: Application of cellulose nanofiber coating on a paper surface. In: Tagungsband zum XIIIth Congress Berlin 2015. Berlin: Laserline; 2015. p. 74.

27. Okayama T, Kadoya C, Seki M, Tonoyama M. Applicability of cellulose nanofiber coating treatment for strengthening naturally aged papers. In: Pan Pacific Conference 2016: current research and perspectives on pulp, paper and lignocellulosic materials; 2016. p. 136-8.

28. Camargos CHM, Junior, JCDF, Pereira FV. Nanocellulose for conservation and restoration of graphic documents. In: experience and evidence; 2016. p. 14.

29. Pereira FV. Nanocellulose-based composites for conservation and restoration of cultural heritage on paper: Comparative studies between traditional and innovative methods (Conference paper). In: TAPPI international conference on nanotechnology for renewable materials 2016; 14th-16th 2016. p. 348-65.

30. Dreyfuss-Deseigne R. Research on the transparency of mending in transmitted light: introduction of nanocellulose in paper conservation. In: experience and evidence; 2016. p. 15. 
31. Arnold RB. ASTM's Paper Aging Research Program. The book and paper group annual 2008. http://cool.conservation-us.org/byauth/arnold/ astm-aging-research/.

32. SawoszczukT, Barański A, Łagan JM, Łojewski T, Zięba K. On the use of ASTM closed vessel tests in accelerated ageing research. J Cult Herit. 2008;9(4):401-11.

33. International Organization for Standardization. Paper, board and pulpsMeasurement of diffuse blue reflectance factor-Part 1: Indoor daylight conditions (ISO brightness); 2009 10.2009.

34. International Organization for Standardization. Paper and board-determination of tensile properties-Part 2: constant rate of elongation method (20 mm/min). Geneve: ISO copyright office; 2008.

35. Caulfield DF, Gunderson DE. Paper testing and strength characteristics. Tappi proceedings of the 1988 paper preservation symposium: 1988 October 19-21; Washington. 1988:31-40.

36. Röhrling J, Potthast A, Rosenau T, Lange T, Ebner G, Sixta H, et al. A novel method for the determination of carbonyl groups in cellulosics by fluorescence labeling. 1. method development. Biomacromol. 2002;3(5):959-68.

37. Röhrling J, Potthast A, Rosenau T, Lange T, Borgards A, Sixta H, et al. A novel method for the determination of carbonyl groups in cellulosics by fluorescence labeling. 2. validation and applications. Biomacromol. 2002;3(5):969-75.

38. Röhrling J, Potthast A, Rosenau T, Sixta H, Kosma P. Determination of carbonyl functions in cellulosic substrates. Lenzinger Berichte. 2002;81:89-97.

39. Hummert $E$, Henniges $U$, Potthast A. Fluorescence labeling of gelatin and methylcellulose: monitoring their penetration behavior into paper. Cellulose. 2013;20(2):919-31.
40. Banik G, Brückle I, editors. Paper and water: a guide for conservators. 1st ed. Amsterdam: Butterworth-Heinemann; 2011.

41. Gardner DJ, Oporto GS, Mills R, Samir MA. Adhesion and surface issues in cellulose and nanocellulose. J Adhes Sci Technol. 2008;22(5-6):545-67.

42. Schmied FJ, Teichert C, Kappel L, Hirn U, Bauer W, Schennach R. What holds paper together: nanometre scale exploration of bonding between paper fibres. Sci Rep. 2013;3(2432):1-6.

43. Blechschmidt J, editor. Taschenbuch der Papiertechnik. 2nd ed. Leipzig: Fachbuchverlag Leipzig im Carl Hanser Verlag; 2013.

44. Moropoulou A, Zervos S. Impact of aqueous treatments on paper strength. Restaurator. 2003;24(3):160-77.

45. Syverud K, Stenius P. Strengths and barrier properties of MFC films. Cellulose. 2009;16(1):75-85.

46. Henniges $U$, Potthast A. Feuchtigkeitsinduzierte Transportvorgänge im Papier. In: Hofmann C, Schäning A, editors. Wasser-Konservieren-Restaurieren: 20 Tagung des Österreichischen Restauratorenverbandes, 10.-11. November 2006, MAK. Wien; 2007. p. 43-7.

47. Zysk-Weise A, Banik G. Veränderungen der Cellulose an nass-trocken Grenzflächen. In: Banik G, editor. Wege zur Konservierungswissenschaft: Projekte am Studiengang Restaurierung und Konservierung von Graphik Archiv- und Bibliotheksgut, Staatliche Akademie der Bildenden Künste Stuttgart, 2000-2008. 1st ed. München: Siegl; 2010. p. 21-4.

48. Junior JLP, Ligterink FJ. Spectroscopic characterization of the fluorescence of paper at the wet-dry interface. Restaurator. 2001;22(3):133-45.

\section{Submit your manuscript to a SpringerOpen ${ }^{\odot}$ journal and benefit from:}

- Convenient online submission

- Rigorous peer review

- Immediate publication on acceptance

- Open access: articles freely available online

- High visibility within the field

- Retaining the copyright to your article 